\title{
Relationship between body fat and body condition score and their effects on estrous cycles of the Standardbred maiden mare
}

\author{
I. Vecchi • A. Sabbioni • E. Bigliardi • G. Morini • \\ L. Ferrari • F. Di Ciommo • P. Superchi • E. Parmigiani
}

Published online: 12 May 2010

(C) Springer Science+Business Media B.V. 2010

\begin{abstract}
Standardbred maiden mares are generally stressed and in poor physical condition because of their incorrect management at the end of their racing careers. The purpose of this study was to identify an objective assessment that, similar to body condition score (BCS) determination, is easy to measure and able to confirm or improve fattening status assessment, as well as to ascertain whether a relationship with reproduction efficiency exists in subjects destined for a first-time insemination program. The authors assessed 29 Standardbred maiden mares ( $7 \pm 2$ years old) during the breeding season. On January 15 (day 0 ), the same operator performed the following on all subjects: the first gynecological and ultrasound examination, a BCS assessment (range 0 to 5), and an adiposity objective assessment (i.e., measurement of fat thickness by ultrasound scan). At day 0 , all mares were in seasonal anestrous. On ovulation day, all subjects exited the study. Both techniques were shown to be significantly and reciprocally correlated $(r=0.976 ; P<0.01)$ to the first seasonal ovulation in maiden mares $(-0.772$ and -0.805 , respectively, for fat thickness and BCS; $P<0.01)$. Based on the results obtained, regression equations for the prediction of days to the first seasonal ovulation (y) were created. The best predictive equation was the following: $\mathrm{y}=26.714 \mathrm{x}^{3}-202.44 \mathrm{x}^{2}+446.04 \mathrm{x}-195.65\left(R^{2}=0.783 ; \mathrm{SE}=17 \mathrm{~d} ; P 0.01\right)$, with an independent BCS variable. In conclusion, this study suggests that increasing the plane of nutrition (i.e., flushing), starting approximately 3 weeks before the breeding season, stimulates ovarian activity in stressed maiden mares.
\end{abstract}

Keywords BCS $\cdot$ Estrous cycle $\cdot$ Performance mare $\cdot$ Ovulation $\cdot$ Body fat

\author{
Abbreviations \\ BCS body condition score
}

I. Vecchi $(\bowtie) \cdot$ E. Bigliardi $\cdot$ G. Morini $\cdot$ L. Ferrari $\cdot$ F. Di Ciommo $\cdot$ E. Parmigiani Dipartimento di Salute Animale Sezione di Clinica Ostetrica e Riproduzione Animale, Parma, Italy e-mail: ilaria.vecchi@nemo.unipr.it

\section{A. Sabbioni $\cdot$ P. Superchi}

Dipartimento di Produzioni Animali, Biotecnologie Veterinarie, Qualità e Sicurezza degli Alimenti, Parma, Italy 


\section{Introduction}

A Standardbred mare's entry into reproduction activities must take place, pursuant to racing regulations, upon the mare turning 8 years old unless the owners choose an even earlier entry. The off-the-track subjects are generally stressed and in poor physical condition because of the incorrect management at the end of the racing career. The role of photoperiod in the regulation of the mare's reproduction activities has been well defined and is critical for the mare's entry into seasonal reproduction. Recent studies showed that the modulatory effects of nutrition, body condition, and climate trigger the onset of the estrous cycle (Ball 2005). The indices allowing an easy assessment of the horse's good physical conditions include the body condition score (BCS). This parameter, assessing the body's subcutaneous fat and, therefore, the animal's energy balance, represents an expression of its physical condition (Christie et al. 2006). BCS is a subjective assessment method for body fat level, used in different species as a response factor in studies on animal nutrition, physiology, and reproduction; assessing changes in fat deposits represents a big advantage, not only for researchers but also for farm staff. Animals with a low BCS can suffer from massive parasitic infestations, systemic pathologies, inappropriate nutritional programs, or insufficient dentistry; on the other hand, a high BCS, which is typical of overweight or obese subjects, can reveal a subtle but chronic inflammatory status (Vick et al. 2007). Both a high and low BCS, unavoidably, affect animal health.

Adipose tissue was long considered a fat-deposit tissue, but now it appears to play an important role in energy homeostasis (Yang et al. 2001); therefore, in all animals, the fat reserves represent an energy source that is necessary to resist stressful periods. Poor fat reserves, when the energy requirements increase, favour the mobilization of muscle proteins for energy purposes. The BCS, based on a subjective visual examination and palpation of specific areas of the horse's body, was developed by Henneke et al. (1983). To be valid, this method must meet three specific qualification parameters: repeatability, reproducibility, and predictability (Suagee et al. 2008). Repeatability exists when a judge assigns the same score for two subsequent moments of the same subject; reproducibility exists when two or more judges assign the same score to the same subject; and predictability exists when the score assigned reflects the actual subcutaneous fat level. The purpose of this study was to identify an objective assessment, similar to BCS determination, which is easy to measure and able to confirm or improve the fattening status assessment, as well as to ascertain whether a relationship between BCS and reproduction efficiency exists in subjects during their first breeding season.

\section{Materials and methods}

For this study, 29 Standardbred maiden mares, which were off the track between 3 and 8 years of age $(7 \pm 2)$, were destined for their first instrumental insemination program in the same breeding season. For the entire duration of the study, the animals did not undergo any treatment that affected their estrous cycle (e.g., light program, treatments with dopamine agonists, etc.). The first gynecological and ultrasound examinations via a transrectal route (Hayes et al. 1985) (Aloka SSD $500^{\circledR}$, linear probe $5.0 \mathrm{MHz}$ ) were performed on all subjects on January 15 (day 0). Concomitantly, the same operator performed the BCS assessment for all mares. Visual inspection and palpation were performed on the following regions: neck, chest, withers, retro-scapula, and coccyx, assigning a final score ranging from 0 to 5 (Carroll and Huntington 1988). The animals were fed maintenance rations 
Table 1 Means and standard deviations (SD) of the data

\begin{tabular}{llllll}
\hline & Fat thickness $(\mathrm{mm})$ & BCS & Weight $(\mathrm{kg})$ & No. of days to 1st ovulation & Age (years) \\
\hline mean & 12.79 & 2.6 & 454.4 & 73 & 7 \\
SD & 6.32 & 0.8 & 61.3 & 35 & 2 \\
\hline
\end{tabular}

based on body weight (Martin-Rosset 1990); the latter was estimated based on the height of the withers (hypsometer) and chest circumference (meter). For objective adiposity assessment, the measurement of the fat thickness was also performed via ultrasound (Lean-meter, Renco Corporation, Minneapolis, MN, USA) approximately $11 \mathrm{~cm}$ from the base of the tail and $10 \mathrm{~cm}$ off the median line (Vick et al. 2007). On day 0, all mares were in seasonal anestrous, clinically healthy, and did not show reproduction-related pathologies (Troedsson 2000). Beginning February 1, the mares underwent gynecological and ultrasound examinations daily. The presence of one or more follicles $20 \mathrm{~mm}$ in size in one or both ovaries without a corpus luteum was defined as a transition phase; a follicle $22.5 \mathrm{~mm}$ or more in size was considered growing; and a follicle was considered dominant when its size reached $30 \mathrm{~mm}$. The presence of a corpus luteum was considered evidence of ovulation (Ginther et al. 2004), and at this stage, the subjects exited the study. All ovulations that occurred during the study were considered non-pathological. The scores relating to the subjective (BCS) or objective (subcutaneous fat thickness) assessment of the mare's body condition at the beginning of the breeding season underwent correlation analysis. The data obtained subsequently underwent ANOVA (SPSS 17.0) using the subcutaneous fat thickness class as a fixed factor, obtained by subdividing the sample into five classes $[\mathbf{1}<7 \mathrm{~mm}(8) ; 2$ 7-10 mm (7); 3 10-17 mm (5); 4 17-20 mm (5); $5>20 \mathrm{~mm}$ (4)]. The mares' age and weight were initially used in the model as covariates, but, having not been found significant, they were removed. Applying multiple regression, estimate equations were created for the day of the first ovulation using either BCS or subcutaneous fat thickness.

\section{Results}

Table 1 shows means and standard deviations of the data recorded for the samples. Subjects with a "poor" physical condition (BCS $\leq 2.5$ and fat thickness $\leq 10 \mathrm{~mm}$ ) showed a greater number of days from the first examination to the first seasonal ovulation than subjects in "good" physical condition. Additionally, there was a tendency for overweight subjects not to undergo ovulation (Table 2).

Table 2 Effects of the mare's body condition on ovulation onset

\begin{tabular}{llll}
\hline Subcutaneous fat thickness class & Subcutaneous fat thickness (mm) & BCS & Ovulation onset (days) \\
\hline 1 & $6.25 \mathrm{a}$ & $1.81 \mathrm{a}$ & $97 \mathrm{c}$ \\
2 & $9.00 \mathrm{~b}$ & $2.14 \mathrm{~b}$ & $96 \mathrm{c}$ \\
3 & $14.40 \mathrm{c}$ & $2.70 \mathrm{c}$ & $69 \mathrm{~b}$ \\
4 & $18.80 \mathrm{~d}$ & $3.30 \mathrm{~d}$ & $29 \mathrm{a}$ \\
5 & $23.00 \mathrm{e}$ & $3.75 \mathrm{e}$ & $44 \mathrm{ab}$ \\
\hline
\end{tabular}

a,b,c,d,e different for $P<0.05$ 
Both techniques were significantly and reciprocally correlated $(r=0.976 ; P<0.01)$ to the first seasonal ovulation in maiden mares $(-0.772$ and -0.805 , respectively, for fat thickness and BCS; $P<0.01)$. Considering the above findings, the following equations to estimate the day of the first seasonal ovulation (y) in Standardbred maiden mares are proposed (see also Fig. 1):

$$
\begin{aligned}
& \mathrm{y}=0.0412 \mathrm{x}^{3}-1.6825 \mathrm{x}^{2}+16.293 \mathrm{x}+51.333\left(R^{2}=0.697 ; \mathrm{SE}=20 \mathrm{~d} ; P<0.01\right) \\
& \mathrm{y}=26.714 \mathrm{x}^{3}-202.44 \mathrm{x}^{2}+446.04 \mathrm{x}-195.65\left(R^{2}=0.783 ; \mathrm{SE}=17 \mathrm{~d} ; P<0.01\right) .
\end{aligned}
$$

In the first equation, the independent variable is the fat thickness, whereas in the second equation, the independent variable is the BCS. The $R^{2}$ and SE values obtained show a slightly higher reliability in the second equation.

\section{Discussion}

The results reported in this study compare two methods for the assessment of an animal's fattening status and show the respective advantages and drawbacks of each, as well as the impact of the fattening status on the onset of the first seasonal ovulation. The animals used represent, using a term belonging to other zootechnical sectors, the "turnover" of a horsebreeding farm. BCS assessment has the advantage of being a non-invasive method, with no cost except for an experienced operator to apply it. The technique of measuring fat thickness by ultrasound scan has the advantage of being an objective measurement but requires the use of instruments and longer performance times. In conclusion, an assessment of an animal's physical condition one month prior to the onset of breeding season (15 February for Standardbred mares) allows a mare's estrous cycle, under physiological
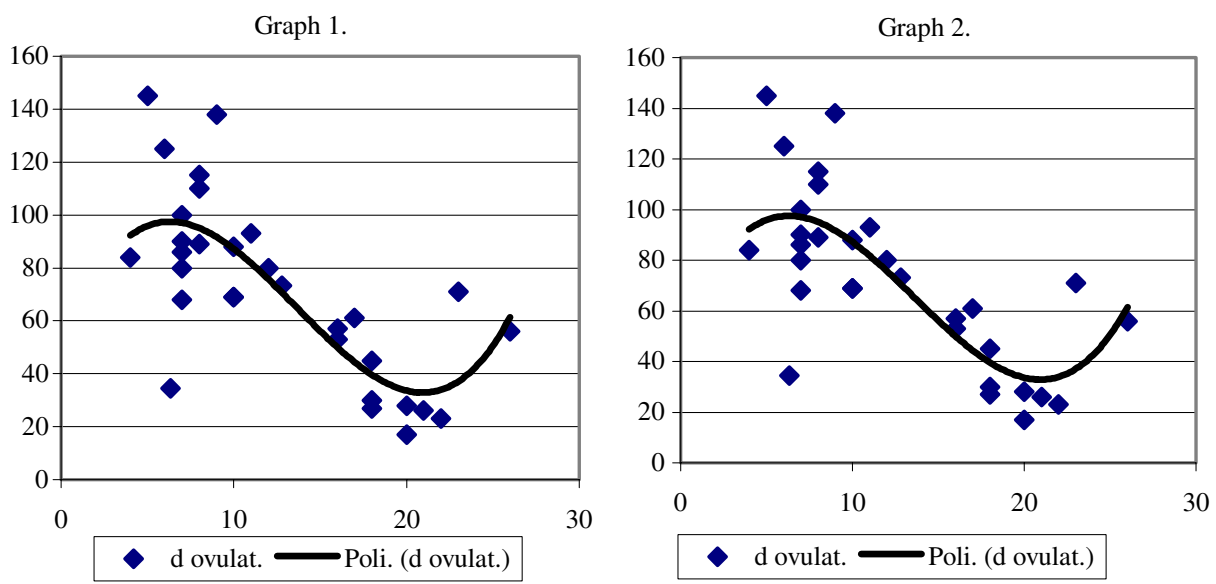

Fig. 1 Estimation of ovulation (days) by fat thickness (left) and BCS (right) assessment 
conditions, to be forecast; therefore, this technique can help the veterinarian apply any remedies, such as a nutritional program (flushing), three weeks prior to breeding to stimulate ovulation. The extension of this study to mares of different breeds and under different environmental conditions is one of our future objectives.

\section{References}

Ball BA (2005) An update on reproductive physiology of the mare. Ippologia 1:23-29

Carroll CL, Huntington PJ (1988) Body condition scoring and weight estimation of horses. Equine Vet J 20:41-45

Christie JL, Hewson CJ, Riley CB, McNiven MA, Dohoo IR, Bate LA (2006) Management factors affecting stereotypes and body condition score in non-racing horses in Prince Edward Island. Can Vet J 47(2): 136-143

Ginther OJ, Beg MA, Gastal MO, Gastal EL (2004) Follicle dynamics and selection in mares. Anim Reprod $1: 45-63$

Hayes KEN, Pierson RA, Scraba ST, Ginther OJ (1985) Effects of estrous cycle and season on ultrasonic uterine anatomy in mares. Theriogenology 24(4):465-477

Henneke DR, Potter GD, Kreider JL, Yeates BF (1983) Relationship between condition scoring, physical measurement and body fat percentage in mares. Equine Vet J 15:371-372

Martin-Rosset W (1990) L'alimentation des chevaux. INRA, Paris, pp 232

Suagee JK, Burk AO, Quinn RW, Petersen ED, Hartsock TG, Douglass LW (2008) Effects of diet and weight gain on body condition scoring in thoroughbred geldings. J Equine Vet Sci 28(3):156-166

Troedsson MHT (2000) Diagnosis and clinical management of ovarian problems. Ippologia 3:51-63

Vick MM, Adams AA, Murphy BA, Sessions DR, Horohov DW, Cook RF, Shelton BJ, Fitzgerald BP (2007) Relationships among inflammatory cytokines, obesity, and insulin sensitivity in the horse. J Anim Sci $85: 1144-1155$

Yang WS, Lee WJ, Funahashi T, Tanaka S, Matsuzawa Y, Chao CL, Chen CL, Tai TY, Chuang LM (2001) Weight reduction increases plasma levels of an adipose-derived anti-inflammatory protein, adiponectin. J Clin Endocrinol Metab 86(8):3815-3819 